F. Reprod. Fert. (1972) 30, 207-211

\title{
LIGHT AND THE TIMING OF OVULATION IN THE GUINEA-PIG
}

\author{
B. T. DONOVAN AND A. N. LOCKHART \\ Department of Physiology, Institute of Psychiatry, De Crespigny Park, London SE5 $8 A F$
}

(Received 16th Fune 1971, accepted 2nd Fuly 1971)

\begin{abstract}
Summary. The effect of differing lighting schedules upon the timing of the influx of leucocytes into the vaginal smear of the guinea-pig, and hence of ovulation, was examined. The timing of this event was altered following advancement of the light-dark sequence by $12 \mathrm{hr}$, and implies that the timing of ovulation in this species is influenced by light.
\end{abstract}

\section{INTRODUGTION}

Light is a potent stimulus influencing gonadal function. Alongside photoperiodic control of the breeding season in many species, the timing of ovulation during the oestrous cycle may be closely integrated with the diurnal sequence of night and day (Fraps, 1962; Critchlow, 1963; Everett, 1964; Donovan, 1970). The guinea-pig has been little studied in this respect although the finding that oestrous behaviour tends to begin at a certain time of night, and varies with changes in the onset of darkness (Dempsey, Myers, Young \& Jennison, 1934), suggests that the release of an ovulatory quantum of gonadotrophin in this species may similarly be initiated at a certain time of day. As a preliminary to more detailed studies of the mechanisms governing ovulation, the effects of changing the daily lighting schedule on the vaginal cycle of this species have been explored.

\section{MATERIALS AND METHODS}

Adult female guinea-pigs of mixed origin were housed in windowless rooms maintained at $18^{\circ} \mathrm{C}$ and illuminated for $16 \mathrm{hr}$ daily. The lights were switched on either at 08.00 or 20.00 hours and the animals examined for vaginal opening at 12.00 and 24.00 hours, with a vaginal smear being taken when appropriate. Thus, the animals were always examined $4 \mathrm{hr}$ after the end of the dark period and just before it began. Vaginal smears were taken by lavage, dried on to a slide, and stained with Ehrlich's acid haematoxylin and eosin Y.

The influx of leucocytes into the vaginal smear after the appearance of cornified cells in the sample was taken as the point of reference for this study. The first smear taken after vaginal opening often contains epithelial cells, cornified cells and leucocytes but, as oestrus approaches, there is a progressive reduction in the number of leucocytes, with the appearance of brightly stained rounded cornified cells, and the end of vaginal oestrus is signalled by a marked rise in the leucocyte count. 


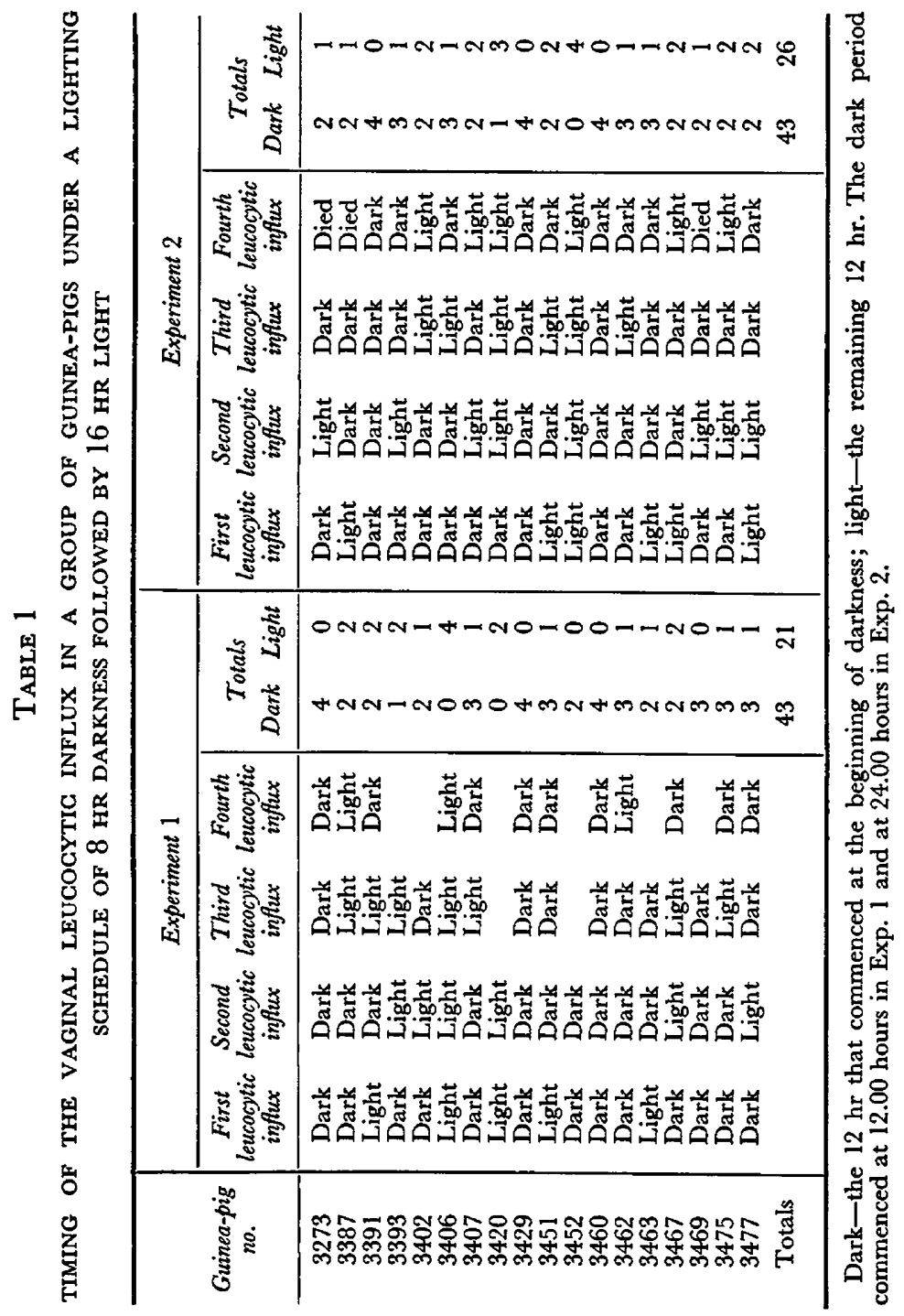


In a preliminary experiment, all the guinea-pigs in the departmental colony of approximately 100 females were examined at 12.00 and 24.00 hours, in addition to the routine daily examination at 09.00 hours, for 7 days. For these animals, the lights were on from 08.00 to 24.00 hours.

Subsequently, in Exp. 1, eighteen females were transferred to a room lit from 20.00 to 12.00 hours and allowed to become accustomed to this regimen for 1 month. Twice daily vaginal examination, at 12.00 and 24.00 hours, was
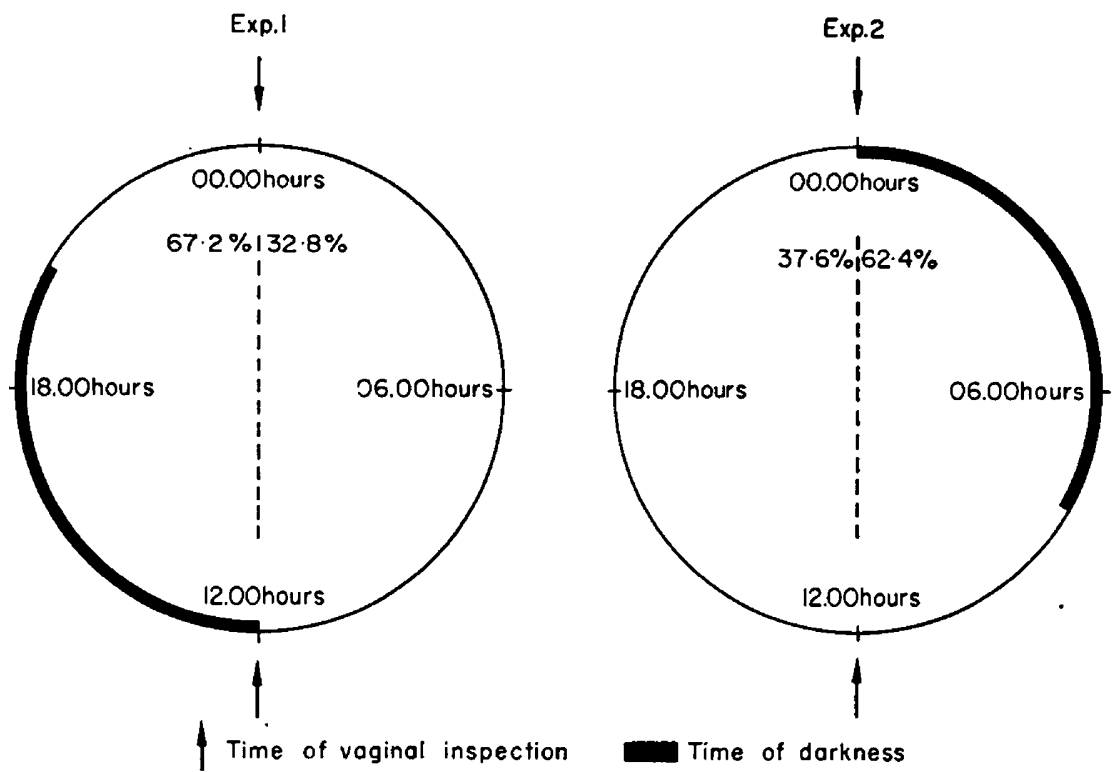

TEXT-FIG. 1. The effect of a change of lighting on the timing of the leucocytic influx into the vaginae of a group of guinea-pigs. Between Exp. 1 and 2, the light-dark sequence was altered by $12 \mathrm{hr}$, but the proportion of animals showing a leucocytic influx during the $12 \mathrm{hr}$ including the dark period remained the same.

then begun and maintained for periods of 1 or 2 weeks with intervals of 1 or 2 weeks over a span of 5 months. In the middle of this period, the lighting was readjusted to be on from 08.00 to 24.00 hours (Exp. 2) so that several oestrous periods could be studied for each animal under each lighting schedule.

\section{RESULTS}

Thirty-nine oestrous periods were recorded in the preliminary experiment and, in twenty-seven instances, the influx of leucocytes occurred between 24.00 and 12.00 hours, the time interval that contained the dark period. This asymmetric distribution is significant (two-tailed exact binomial test) at the $2.5 \%$ level, and exhibits a pattern similar to that observed with behavioural oestrus by Dempsey et al. (1934).

The effects of a change in the timing of illumination are summarized in Table 1 and Text-fig. 1. Sixty-four periods of vaginal oestrus were observed 
while the animals were illuminated from 20.00 to 12.00 hours and in fortythree of these, the influx of leucocytes into the vaginal smear occurred between 12.00 and 24.00 hours. Sixty-nine oestrous periods were observed in the same group of animals after altering the onset of illumination by $12 \mathrm{hr}$ and, on fortythree occasions, the influx of leucocytes into the vagina occurred between 24.00 and 12.00 hours. Statistical analysis of these findings showed that the tendency for this vaginal change to occur during the $12 \mathrm{hr}$ containing the dark period was significant at the $5 \%$ level. Oestrous cycles of normal length continued during the experiments.

\section{DISCUSSION}

These results demonstrate that the occurrence of vaginal oestrus in the guineapig is correlated with the light-dark sequence of environmental illumination, and that the influx of leucocytes tends to take place during or soon after the dark period.

In evaluating these findings, the significance of the vaginal index employed needs to be established. Stockard \& Papanicolaou (1917) first related changes in the vaginal smear to concurrent events taking place in the ovaries and found that ovulation and the entry of leucocytes into the vaginal fluid tended to be coincident. Leucocytic infiltration of the vaginal smear after complete cornification has been taken to indicate ovulation by Young, Myers \& Dempsey (1933) and Hermreck \& Greenwald (1964). It is likely that the influx of leucocytes arises under the influence of progesterone. Oestrogen alone has failed to cause normal vaginal cornification and typical changes following oestrus were lacking after withdrawal of this steroid but, when oestrogen-primed ovariectomized guinea-pigs were given progesterone, the vaginal smears were similar to those of intact animals at oestrus and leucocytes entered the vaginal lumen $15 \mathrm{hr}$ after steroid injection (Ford \& Young, 1951). We have confirmed this finding in experiments involving the hourly collection of vaginal smears after the subcutaneous administration of $5 \mathrm{mg}$ progesterone to oestrogen-primed ( $25 \mu \mathrm{g}$ oestradiol benzoate/day) spayed females. The change from an oestrous to a metoestrous smear was rapid and was completed between consecutive examinations of the vagina. Measurements of the concentration of progesterone in arterial plasma indicate that a surge of progesterone secretion from the ovaries occurs approximately 8 to $12 \mathrm{hr}$ before ovulation (Feder, Resko \& Goy, 1968), while the relationship between gonadotrophin secretion and ovulation can be assessed from the finding of Myers, Young \& Dempsey (1936) that ovulation took place some 10 to $12 \mathrm{hr}$ after the onset of oestrus, and that the latency between gonadotrophin administration and the manifestation of oestrous behaviour was $6 \mathrm{hr}$ (Dempsey, Hertz \& Young, 1933), thus giving an estimate of 16 to $18 \mathrm{hr}$ for the time interval. Following the intravenous injection of $500 \mu \mathrm{g} \mathrm{LH}$ (Armour Lot No. E 13210), ovulation has, in fact, been reported to occur within 16 to $18 \mathrm{hr}$ (J. E. Booth, unpublished work). Thus, the influx of leucocytes into the vaginal smear occurs around the time of ovulation.

It is clear that, in the guinea-pig, the timing of gonadotrophin release, as measured by the onset of oestrus (Young, Dempsey \& Myers, 1935) or the 
timing of the leucocytic influx into the vagina, shows considerable individual variation, unlike the situation in some strains of rat where this event occurs at a constant time of day among females kept under similar lighting conditions (Everett, 1964). Whether this is due to a lesser influence of environmental factors in the triggering of gonadotrophin secretion in the guinea-pig, or whether it arises as an after-effect of the action of progesterone during the long luteal phase of the oestrous cycle, remains to be determined. Hoffmann \& Schwartz (1965) indicate that the mechanism controlling ovulation in the rat operates in a different manner after an influence of progesterone has waned than in the normally cyclic animal.

\section{ACKNOWLEDGMENTS}

We wish to thank the Science Research Council for a Scholarship (to A.N.L.) and the Population Council for their support of this work.

\section{REFERENCES}

CRrrchlow, V. (1963) The role of light in the neuroendocrine system. In: Advances in Neuroendocrinology, p. 377. Ed. A. V. Nalbandov. University of Illinois Press, Urbana.

Dempsey, E. W., Hertz, R. \& Young, W. C. (1933) The experimental induction of oestrus (sexual receptivity) in the normal and ovariectomised guinea pig. Am. J. Physiol. 116, 201.

Dempsey, E. W., Myers, H. I., Young, W. C. \& Jennison, D. B. (1934) Absence of light and the reproductive cycle in the guinea pig. Am. 7. Physiol. 109, 307.

Donovan, B. T. (1970) Mammalian neuroendocrinology. McGraw-Hill, London.

EvereTr, J. W. (1964) Central neural control of reproductive functions of the adenohypophysis. Physiol. Rev. 44, 373.

Feder, H. H., Resko, J. A. \& Goy, R. W. (1968) Progesterone concentrations in the arterial plasma of guinea-pigs during the oestrous cycle. F. Endocr. 40, 505.

Ford, D. H. \& Young, W. C. (1951) The role of progesterone in the production of cyclic vaginal changes in the female guinea pig. Endocrinology, 49, 795.

FRAPs, R. M. (1962) Effects of external factors on the activity of the ovary. In: The Ovary, Vol. 2, p. 317. Ed. S. Zuckerman. Academic Press, London.

Hermreck, A. S. \& Greenwald, G. S. (1964) The effects of unilateral ovariectomy on follicular maturation in the guinea pig. Anat. Rec. 148, 171.

Hofrman, J. C. \& SchwarTz, N. B. (1965) Timing of ovulation following progesterone withdrawal in the rat. Endocrinology, 76, 626.

Myers, H. I., Young, W. G. \& Dempsey, E. W. (1936) Graafian follicle development throughout the reproductive cycle in the guinea pig, with special reference to changes during oestrus (sexual receptivity). Anat. Rec. 65, 381 .

Stockard, G. R. \& Papanicolaou, G. N. (1917) The existence of a typical oestrous cycle in the guineapig-with a study of its histological and physiological changes. Am. J. Anat. 22, 225.

Youno, W. C., Dempsey, E. W. \& MYers, H. I. (1935) Cyclic reproductive behaviour in the female guinea pig. F. comp. Psychol. 19, 313.

Youne, W. C., Myers, H. I. \& Dempsey, E. W. (1933) Some data from a correlated anatomical, physiological and behavioristic study of the reproductive cycle in the female guinea pig. Am. $\mathcal{F}$. Physiol. 105, 393. 